\title{
Beyond Bandwidth: Dimensions of Connection in Interpersonal Communication
}

\author{
BONNIE A. NARDI \\ University of California, Irvine School of Inf. + Computer Science, 444 Computer Science \\ Building, Irvine, CA 92697,USA (E-mail: nardi@ics.uci.edu)
}

\begin{abstract}
Computer-mediated communication (CMC) is a keystone of computer-supported collaborative work. Current CMC theory utilizes an information channel metaphor in which media vary according to how well they afford the transfer of messages in the channel, i.e., bandwidth. This paper draws attention to a different aspect of communication argued to be equally important: a relation between people that defines a state of communicative readiness in which fruitful communication is likely. Drawing on research on instant messaging (Nardi et al., 2000) and face to face communication (Nardi et al., 2002; Nardi and Whittaker, 2003), as well as related literature, three dimensions of connection that activate readiness are proposed: affinity, commitment, and attention. These dimensions comprise a field of connection between dyads. A field of connection is conceptualized as a labile, multidimensional space in which the values of the dimensions vary according to the history of communicative activity. Affinity, commitment, and attention are constantly monitored, negotiated, and managed through social bonding, expression of commitment, and capture of attention. The management of fields of connection requires significant interactional work to sustain communication over time.
\end{abstract}

Key words: affinity, attention, commitment, computer-mediated communication, interpersonal communication, social connection

\section{Introduction}

To communicate with ease, we must come to feel connected to each other, we must experience mutual commitment to joint undertakings, and we must gain each others' attention. These activities are at the heart of interpersonal communication. The focus of much computer-mediated communication theory, however, is on the media themselves, in particular, on the amount and type of information flowing through "channels" of varying "bandwidth." Media richness theory (Daft and Lengel, 1984), for example, assessed the extent to which media allow exchanges of information with rapid feedback, in "languages" such as body language or mathematical notation, and in audio or visual modes. "Rich" media, such as video, allow ample information transfer while "lean" media like text, allow little. Social presence theory (Short et al., 1976) analyzed how well media provide information 
about the "presence" of others including facial expression, tone of voice, and attributes such as goals and attitudes. Work on awareness evaluated media according to whether they afford knowledge of others' whereabouts and activities (Heath and Luff, 1991; Dourish and Bly, 1993; Gutwin and Greenberg, 1998, Tang et al., 2001; Begole et al., 2002).

In ethnographic investigations of instant messaging in the workplace (Nardi et al., 2000) and communication in personal social networks in the workplace (Nardi et al., 2002; Nardi and Whittaker, 2002), open-ended interviews yielded many data that seemed to have little to do with the kinds of communicative activity suggested by the need for information bandwidth. The data pointed instead to activity geared to establishing feelings of connection with others for the purpose of continued interactions over time. A feeling of connection is a subjective state in which a person experiences an openness to interacting with another person.

The ethnographic data showed that feelings of connection were accomplished through interactions involving (1) the body and (2) informal discourse of low information content. This paper distinguishes between communicative activity that establishes feelings of connection that ready people for further interaction with each other, and communicative activity in which information is exchanged.

It is proposed that activities of connection establish a field of connection between dyads in which social and affective connections are stimulated in order to ready people for further communication (typically of an informational nature). A field of connection is a labile multidimensional space comprised of feelings of affinity, commitment, and attention. These dimensions of connection must be kept in a state of sufficient excitation or activation to promote effective communication in which participants can exchange information. The paper describes the work of creating and sustaining connection as it emerged in informants' accounts. An argument is made that such work is central to communication and has not been a focus of previous research on computer-mediated communication.

We begin with a simple example from a study of instant messaging (Nardi et al., 2002). An executive at a telecommunications company described his use of instant messaging (IM) with a co-worker:

Alan: On weekends I occasionally log on from home and Rick is working and I say hi.

Interviewer: What's the purpose of that?

Alan: Just to say hi. There's no purpose and nothing to say.

While we would not be surprised to find teenagers just saying hi in IM (Lenhart et al., 2001; Grinter and Palen, 2002; Schiano et al., 2002), it warrants explaining when a well-regarded, highly paid executive reports such 
behavior. It is argued that Alan was not frittering his time away, but doing useful communicative work - what we can call the work of connection. By staying in touch with his colleague Rick, he readied a field of connection for future interaction. Alan stated that his message had no instrumental purpose or contentful substance: "There's no purpose and nothing to say." He was engaging in one of the thousand small daily interactions we all engage in, almost unconsciously, to maintain connection to others.

What about Rick? Was he open to such overtures? Rick explained that he liked to monitor his instant messaging buddy list so he could feel a sense of connection with co-workers:

Rick: You can see when people log in and out and when they're off to lunch. It's kind of neat to watch people's comings and goings and it's not so much tracking it but you hear the sound of the door clicking and notice that somebody that everybody's looking for is back ... you get a visual image in your mind of that person and I feel closer to the people I work with as a result of that.

The activity of connecting to others, then, often (though not always) engenders mutual satisfaction (Baumeister and Leary, 1995). People desire and seek connection, as Rick stated in explaining that he felt closer to others in virtually seeing and hearing them through instant messaging. This "closeness" attained through instant messaging was not about gathering information from others, but about the pleasure of experiencing a social bond.

We rarely call attention to, much less theorize about, such activity. In activity theory terms (Kaptelinin, 1996), acts of communicative connection often occur at the operational level of well-practiced habitual behaviors, devoid of conscious goals, as we saw with Alan's "hi." Such activity is typically so unremarkable and everyday as to be nearly invisible (Nardi, 1998).

Activities of connection lack straightforward manifestations such as the turn taking, head nodding, and conversational openings and closings so useful in conversation analysis (Garfinkel, 1967; Sacks et al., 1974; Sacks, 1992). Activities of connection caught my attention through analysis of informants' accounts of their communicative activities which they often described in vignettes with nuanced contextual details. These vignettes are taken as primary data, as expressive of informants' thoughtful reflections on their own communicative activity (in the spirit of ethnomethodology and ethnography as developed in anthropology). The paper provides as much data from the accounts as possible, as well as background information from the ethnographies, to aid the reader in evaluating this account of communicative connection. 
While the present data are qualitative, once the basic principles concerning the dimensions of connection are known, it may be possible to devise measures using numerical scales, rankings, or other means. A subjective state of openness to communication with another, for example, will clearly vary, and could be measured. Other dimensions of connection may exist beyond those explored in this research, and they may exist in units larger than dyads. This paper is a first attempt to conceptualize dimensions of connection with the available data.

\section{Background on the ethnographic studies}

This work draws on a study of instant messaging in the workplace ("the IM study") (Nardi et al., 2000) and a study of personal social networks in the workplace ("the netWORK study") (Nardi and Whittaker, 2002; Nardi et al., 2002). The IM study investigated the use of instant messaging of 20 people. Seven worked at a large telecommunications company. Twelve worked at an Internet company of about 700 employees. An additional participant was an independent contractor. The sample included executives in charge of technology transfer, a marketing specialist, graphic artists, software developers, Web designers, administrative assistants, and others. Usage of IM included colocated workers (sometimes only a cubicle or two away), workers separated by as much as a nine hour time difference, and non-colocated workers at shorter distances. Informants were experienced users of a variety of technologies, including email, voicemail, PC, and Web applications.

Informants were asked about their jobs and their use of IM, as well as other communication technologies. They were asked to talk about the advantages and disadvantages of using IM, and how it compared with other communication media such as telephone, voicemail, email, and face-to-face interaction. Interviews were audiotaped and conducted in informants' workplaces. The researchers observed workers and videotaped some sessions of IM use. It was possible to observe incoming instant messages as the interview proceeded in many cases. Informants would sometimes pause and let the researchers see a message, and show their response if they chose to respond. The bulk of the data was from interviews and observations supplemented with logs of some IM sessions. These logs were drawn from one site only. At the other site the legal department prohibited the collection of logs.

The netWORK study reported findings from an investigation of workers' personal social networks and the work needed to create and maintain them (hence "netWORK"). The researchers carried out in-depth interviews and observations in a sample of 22 people in 12 organizations. The sample included public relations specialists, a telecommunications executive, an attorney who appeals life sentence cases, graphic artists, Web designers, a 
non-profit consultant, small business owners, Internet company executives, and an administrative assistant. Some were independent contractors or consultants. Some worked for a large telecommunications company, some for a medium size Internet portal company, and some for small companies of fewer than 100 people, including an animation and Web company, and a company that produced Web pages, CD-ROMs, and user interfaces for computer games. All were proficient with a variety of communication technologies.

Observations and audiotaped interviews were conducted in informants' workplaces. Informants were asked about their work and how they communicated, including usage of phone, cell phone, voice mail, conference calls, fax, Federal Express, email, email attachments, videoconferencing, pagers, the Internet, FTP, the Web, chats, intranets, and extranets, and face to face communication. All informant names in both studies have been changed as have identifying details.

Across the two studies, informants were approximately half male and half female. Most were of Anglo-American or Asian-American descent. A small number were born in Europe. Most resided in the San Francisco Bay Area, with some in New Jersey.

\section{Theories of computer-mediated communication}

This section briefly considers theories of computer-mediated communication. It discusses the widespread adoption of the channel/bandwidth metaphor in CMC theory. The reader is referred to two excellent reviews of CMC theory for further detail (Walther and Parks, 2002; Whittaker, 2003).

Walther and Parks (2002) and Whittaker (2003) established the channel metaphor as central to CMC theory. Whittaker (2003) observed, "The fundamental goal of mediated communication theories has been to explain the relationship between the affordances... of different mediated technologies and the communication that results from using these technologies." An affordance in this context is a capability to convey information, including interactive feedback such as head nodding or smiling, acknowledgment that the communication has been understood, and basic linguistic information (Whittaker, 2003). In their review, Walther and Parks (2002) noted, "sender, receiver, channel, and feedback" are "familiar communication components" of CMC theory, including current theorizing.

The channel metaphor goes back to some of the earliest work on mediated communication. Ryan and Craig characterized technologies in terms of how well "information can be transmitted and received by any of the five senses" (cited in Williams, 1977, pp. 2-3). In this view, face to face communication is especially rich because a shared physical environment provides mutually 
viewable objects about which people may converse and to which they refer verbally and through deictic reference. A great deal of other work has focused on the sharing of rich information in the physical environment and its importance for communication (Kahneman, 1973; Argyle and Graham, 1977; Bly, 1988; Whittaker et al., 1993, 1994; Kraut et al., 1996; Nardi et al., 1996; Moran et al., 1998; Mynatt et al., 1999; Kraut et al., 2002; Olson et al., 2002).

Media richness theory (Daft and Lengel, 1984) defined richness as "the potential information-carrying capacity of data." The richest medium is face to face communication and the leanest is "numeric formal" documents such as computer output. Daft and Lengel analyzed media according to their capability to provide feedback, in terms of the number of channels (e.g., audio, visual) they support, the source of information (personal/impersonal), and the language used (body, numeric, etc.).

Social presence theory considered the importance of creating a sense of "presence" of the person with whom a participant is communicating. Short et al. (1976) discussed the extent to which media present a sense of others' goals, attitudes and motives. Information about others' bodies - what they look like, body language, facial expression - as well as the body's accouterments including clothing, makeup, hairstyle, and jewelry, are key aspects of presence (Short et al., 1976). Walther and Parks (2002) summarized social presence research: "...the greater the bandwidth a system affords, the greater the social presence of communicators." Information about attitudes and motives as well as what can be derived from assessing clothing and so forth, is critical to communication. The use of social presence cues is highly social in nature, but distinct from the management of social connection between people, which, I will argue, is established in other ways.

Research on awareness evaluated technologies on the extent to which they are capable of generating a sense of the presence of others (Heath and Luff, 1991; Dourish and Bellotti, 1992; Dourish and Bly, 1993; Gutwin and Greenberg, 1998; Bradner et al., 1999; Churchill and Bly, 2000; Milewski and Smith, 2000; Tang et al., 2001; Begole et al., 2002; Weisband, 2002). That presence may simply be knowing someone is available in their office (Fish et al., 1992; Tang et al., 1994; Tang and Rua, 1994), or knowing that they can be "waylaid" outside of their office (Bly et al., 1993; Fish et al., 1992; Mantei et al., 1991; Heath and Luff, 1992), or even providing high fidelity presence through high bandwidth video (see Finn et al., 1997). This work expands social presence theory and takes it in new directions, emphasizing participants' ability to gather information as to whether others are available for communication.

The symbolic interaction perspective of Trevino et al. (1987) considered symbolic reasons for choosing particular media. A medium may be selected to show "a desire for teamwork, to build trust, or convey 
informality... urgency... personal concern... or [deference]." Trevino et al. observed, "Managers apparently pick face to face to signal a desire for teamwork, to build trust, [and so forth]." In this formulation, managers are transmitting "signals" to recipients (see also Iacono and Weisband, 1997; Bos et al., 2002). The signals map to the choice of a particular medium, creating a closed system of a small number of medium/signal mappings which can send a limited number of messages. The factors of interest, such as trust and personal concern, move in the direction of establishing fields of connection, but the framing is of signal transmission, rather than mutual connection and readiness.

Whittaker noted that an important stream of CMC theory utilizes the notion of "social cueing" in mediated communication. "Here the focus is on the role of visual information in supporting the transmission of affective and interpersonal information" (Whittaker, 2003). Social cueing theory (Morley and Stephenson, 1969, 1970; Short et al., 1976; Sproull and Kiesler, 1986; Rutter, 1987) encompasses both social presence theory and research on the effects of the absence of visual cues in mediated communication (Kiesler et al., 1984; Culnan and Markus, 1987; Rutter, 1987). The latter work analyzes the effects of reduced social cues in media such as email. Gaze, for example, indicates attitude or affect, contributing to "the communication of interpersonal information" (Whittaker, 2003), as do facial expressions (Ekman, 1982; Schiano, 2001).

The emphasis in social cueing theory is not on establishing social connection for the purpose of sustained interaction, but on participants' ability to gather visual information on other participants" "affective and attitudinal state" (Whittaker, 2003). The extent to which such information is needed for tasks like negotiation or problem solving is assessed. Social cueing theory focuses on analyzing specific bounded communicative tasks, such as a particular discussion or negotiation, rather than looking at communicative readiness over time. In social cueing theory a participant "reads" other participants' visual cues, enabling her to conduct a task such as negotiation more effectively by evaluating, for example, whether she is being understood, whether there is agreement, whether she still has the floor. In establishing communicative connection, the participant is not reading cues but is reaching out to others to establish links for sustained communication.

Clark's theory of common ground (1992) proposes that participants make sense of each other's discourse by establishing shared knowledge. The opening line of Arenas of Language Use is: "Common ground is a type of shared information" (Clark, 1992). Ways of feeling connected such as eating and drinking together, or sharing informal chat with little or no content, are not part of the theory of common ground. Clark's work is rooted in earlier research by Karttunen and Peters (1975) and Stalnaker (1978). Stalnaker stated, "Presuppositions are what is taken by the speaker to be the common 
ground of the participants of the conversation, what is treated as their common knowledge or mutual knowledge (Stalnaker, 1978, emphasis in original). The work of Karttunen and Peters, Stalnaker, and Clark is part of a lengthy tradition in linguistics and psychology that approaches communication through analyzing propositional knowledge. It is straightforwardly information-based. The information contained in common ground is what enables participants to understand each other. "It is ultimately this ... common ground that determines the possibilities against which [participants] try to interpret both words and the world" (Clark, 1992).

Fields of connection and common ground, could, in a more comprehensive theory, work together to explain how interaction is sustained over time. Common ground is a state of shared knowledge (explicitly verbalized or inferred) between participants, increasing over time as they converse, while a field of connection is a labile state of readiness that degrades over time unless interactions of a specific nature occur. The former increases linearly and the other is cyclic, but both processes engage a significant temporal dimension, showing how participants manage communication over time.

Walther's social information processing theory (SIP) posits that "communicators exchange social information through the content, style and timing of verbal messages online" (Walther, 1992). SIP goes beyond bandwidth in suggesting that the timing, rather than simply the information content, of a message may be crucial to communication. In later work, Walther and Parks (2002) expanded SIP to observe that, "The effects of the CMC channel depend not on bandwidth alone, but on the interactions of media characteristics with social contexts, relational goals, salient norms, and temporal frames that promote or inhibit the strategic use of $\mathrm{CMC}$ in relationally supportive or detrimental ways."

Walther and Parks' discussion invites the elaboration of fields of connection in which a wider frame of reference is introduced. While their retention of the "channel" metaphor seems insufficient to handle the expanded scope they propose, they do point to the importance of social context, goals, norms, and time. The present work considers the social contexts, goals, and temporal patterning of communication, in line with Walther and Parks' (2002) recommendations.

\section{Affinity, commitment, and attention}

We turn to empirical evidence for the dimensions of connection - affinity, commitment and attention - as they emerged in the analysis of interview and observational data in the IM and netWORK studies. The empirical findings of others are also utilized. The lability of the dimensions of connection are documented and the ways in which they differ from simple notions of information transfer are noted. 


\subsection{AFFINITY}

Affinity is defined here as feelings of connection between people. A feeling of connection, as stated, is an openness to interacting with another person. Affinity is achieved through activities of social bonding in which people come to feel connected with one another, readying them for further communication. Activities that promote social bonding include:

1. touch

2. eating and drinking

3. sharing experience in a common space

4. informal conversation

The first three involve the body. The fourth involves discourse that is often patently content-free ("nice weather we're having") or of whimsical, entertaining, or superficial content such as jokes or pleasantries.

\subsubsection{Touch}

Touch is a powerful means of creating social bonds. People shake hands or otherwise touch each other upon being introduced. Face to face introductions are deeply valued in part because people have the opportunity to make physical contact. When we touch to create a social bond, we are not collecting information about what someone feels like; the meaning of the encounter is grounded directly in the act of touching and having been touched. AT\&T's clever advertising campaign declared, "Reach out and touch someone." It's hard to improve on that pithy formula; touch is the most powerful way to create a bond through the movement - reaching - of the body towards another body.

In the following interview segment we see how touch was used to create a new field of connection and to renew an existing one. Carl, a public relations specialist at a telecommunications company, "TelCo," described how he managed the introduction of a famous journalist to TelCo's CEO at a high profile invitational gathering for the American media sponsored by TelCO:

Carl: In fact, "Ken Swift" [a well-known journalist], is a very important guy, obviously. I am probably a little far down the food chain for him to spend a whole lot of time with. But I can get a[n] [email] reply from him based on - he'll shoot me back an email, but it's based somewhat on the fact that when he walked in here [to the media event], he walks in and says, "Hey, I'm sure there's a line to meet the big guy, right?" [i.e., the CEO]. It's like, "Ken! Didn't I introduce you to the last big guy? Come on!" Actually I was able to kind of deliver him right into - I looked around, saw where [the CEO] was, and actually, Gail was with him then. She was right at his elbow. So I like - I grabbed her. I said, "Ken wants to meet him. I'm bringing him right over." And Ken and Gail are good friends. I was able to 
like deliver Ken right into Gail's arms; you know, big hug, right at the elbow of [the CEO]. That's going to make him answer my next email.

Carl's discourse is full of bodies touching - "I grabbed her," "big hug," "right at the elbow," "into Gail's arms." The bodies are making quick connection with high impact. There is no discussion of particular aspects of the social presence of the participants or specific signals that might be transmitted; it is a raw assemblage of arms, elbows, hugs, and grabs that Carl reported. Carl's focus was on bringing the bodies together in the right configuration so they could touch. He acted quickly, knowing a major opportunity when he saw one. The event fostered both the new bond formed between Ken and the CEO, and the renewal and intensification of existing social bonds for Ken and Gail, and Ken and Carl.

Why did Carl report this experience in such detail? It was after all, merely an introduction (albeit one involving two well known people). A perennial problem for Carl was to get busy journalists to respond to him. As a public relations specialist, Carl had to maintain active fields of connection with journalists, fields with a sufficient level of activation that the journalists would, as Carl operationalized it, "answer my next email." Carl mentioned the problem twice in the interview segment, and spelled out that it was the high touch introduction that was the solution. A repeated theme in the interviews was the tendency of social bonds to degrade over time. Fields of connection are characterized by short, volatile cycles of ascent and decline, highly sensitive to recent communicative activity.

Let's look more closely at the language Carl used to describe this episode. The ironic, calculating discourse ("a little far down the foodchain," "That's going to make him answer my next email") contrasts vividly with the engaged, emotional description of getting all those bodies in the right place at the right time. Although the media event was quite thrilling and Carl was paying close attention to its emergent possibilities, at the same time he was thinking ahead to the mundane realities of working around annoying journalistic habits. Carl assessed the low level of excitation in his current field of connection with Ken and sought to increase it with the introduction. Here we see the detached, objective work of monitoring the state of the dimensions of connection executed nearly simultaneously with the exciting body work in which touch created and reinforced social bonds.

Evidence for the tendency of the dimensions of connection to weaken over time comes from the fact that though Carl had introduced Ken to a previous CEO (as he did not fail to remind Ken), getting Ken to respond was a continuing problem. Carl opportunistically solved the problem - at least for the next little while - through the dramatic high-touch introduction. In another part of the interview, Carl affirmed the need for the work of com- 
municative renewal in general, mentioning that the media event was a great way to "refresh my list," as he put it - to make personal face to face contact with many of the journalists he dealt with, to refresh social bonds.

Further empirical investigation is needed to describe more precisely the pattern of rise and fall in the dimensions of connection. It is possible that bonds weaken slowly over time, but can be reactivated relatively quickly, especially with adroit use of high-impact contact such as Carl devised. Decay and renewal may be asymmetrical, an efficient arrangement by which people cannot simply neglect others if they expect to be connected, but which does not require the expenditure of huge amounts of energy when it is time to renew connection.

Carl's introduction of the journalist and the CEO revolved around touch. Touch is, in various contexts, healing, comforting, nurturing, arousing. Its power in social bonding may be that it is ambiguously any or all of these, potentially, but not any of them explicitly. If "messages" are being sent via touch, we don't actually know what they are. Touch operates in part at a basic primate level. In a set of famous experiments, Harlow and Harlow (1962) showed that infant monkeys deprived of their mothers chose a cloth surrogate over a wire surrogate, even though both offered the same food. Research going back decades (e.g., Carpenter, 1942) has demonstrated the importance of grooming in non-human primates. Grooming (in which an animal combs through a partner's hair for nits or to smooth the hair) may serve a hygienic function, but it is primarily a means of social bonding in non-human primates (Parr et al., 1997). Grooming does not occur between random animals, but usually between animals of variable status. For example, in Parr et al.'s research, alpha female capuchin monkeys performed more grooming than they received (Parr et al., 1997). Status differences between groomer and groomee vary by species, but in all indicate that grooming enables bonding as grooming is used to establish and maintain bonds among animals at different levels in the status hierarchy (Parr et al., 1997). Barrett et al. (2000) found that baboons just beginning a cooperative relationship engaged in short grooming sessions, while "longer bouts [of grooming] reflected established partnerships." Even in lower primates, then, dyadic relationships have temporal contours associated with bonding activity.

Parr et al. (1997) observed, "[Much research on grooming] favors an explanation of social bonding based on the calming and tension-reducing effects in both participants" (1997). Grooming appears to be grounded directly in the power of touch as it calms and helps reduce tension - in both animals, despite status differences. The animal pleasure of touch we all experience is indisputable. As currently modeled, channel-oriented CMC theory, with straightforward messages and signals, does not explain the power of touch in communication. 
A sense of the power of touch is woven into everyday speech. We say we are "in touch" or "out of touch." Healers (both Western and non-Western) heal through "the laying on of hands." Politicians still "press the flesh," despite the fact that in modern nation states they cannot possibly shake the hands of even a fraction of their potential supporters. In handwritten communications, the conventions " $\mathrm{X}$ " and "O" have long meant hugs and kisses. Both friendship and romance can be effectively promoted with a liberal application of XXXXXX's and OOOOO's to the end of a letter or note. Costume jewelry bearing these letters is a popular item for young girls in the United States.

Of course not all touch enables social bonding. Touch can be used to indicate displeasure, such as poking someone in the chest, or aggressively, to gain power. It is critical to examine the context in which touch is used. The ethnographic detail supplied here to contextualize interactions, along with informants' statements about the interactions involving touch, are meant to show the particular ways in which touch commonly operates in everyday communicative activity.

The dyadic bonds that occurred through the hugs and handshakes at the media event occurred in the social context of a wider set of physical connections. The intensity of this particular bonding was in part a function of the dramatic backdrop of the many arms, elbows, and grabs of the participants, going beyond those of the dyadic relations. The stimulation of the presence of others' bodies again occurs probably in part at a primate level.

Such intensity is more difficult to create in mediated communication where the visceral impact of others' bodies in a shared space can only be simulated. Nonetheless, touch is most definitely simulated in mediated interaction. Braithwaite et al. (1999) studied an online community for people with disabilities, coding all messages sent within a one-month period in 1995 . They found that $6.9 \%$ of all messages communicated "physical affection," including hugs, hand holding, kisses, and shoulder patting. In the instant messaging study, one informant noted that he often sent his girlfriend a quick IM during the day to say hello, which was, as he put it, "like a pat on the shoulder" (Nardi et al., 2000).

Mediated communication transforms visceral experience to verbal messages only (Hobbs, 1980). In face to face interaction, bonding is attained in part through message sending, but increased intensity can be achieved with a staging in physical space where touch and bodies, one's own and others', may be brought into play. Carl's adroit rapid-fire improvisation of a social context in which participants could touch each other in the company of selected special others was an effective means for him to connect the journalist and the CEO, and to connect himself with the journalist.

Of course, we can step back and look at the entire media event as a carefully managed staging within which just such encounters as Carl 
recounted would hopefully take place. In informal ethnographic conversation with the planner of the media event, she described how much work it was to compile the guest list, to make sure that the right people would show up to mingle. She spent a great deal of time consulting people in her social network to ask for names, and wooing special people to persuade them to attend. While the paper has identified the unconscious operational level of much relational activity, it is also true that people are consciously aware of the vital need to maintain connection. They sometimes seek elaborate means of doing so, as in the media event, an expensive, meticulously planned gathering, thoughtfully designed and executed.

In mediated communication, messages must substitute for touch and for the impact of the presence of others' bodies. Walther and Parks (2002) observed that people may substitute "the expression of impression-bearing and relational messages" for information available in face to face communication. While they did not spell out what the "information" in the face to face situation might be, I suggest that it is touch and the presence of bodies, not simply information, that must be substituted for in mediated communication. The persistent feeling that there is a "real" world which is different in kind than the "virtual" world, perhaps derives in part from the transformation of powerful physical experiences that are not technologically or verbally mediated to experiences which seek the same effect but are now mediated through messages only (see Dourish, 2001).

Even in the mediated situation, however, people may attempt to portray a vivid sense of others' bodies, to heighten engagement for increasing affinity. In the group Braithwaite et al. studied, "Rita" was returning after a hospitalization. The other members welcomed her back. "Sally" encouraged Rita's renewed participation with the following:

Sally: Get yourself back to [the chatline]!! Everyone has been asking about you!! Hear me???...Y You gotta help defend the females! Those ole turkeys [the men] are up to something...Hope this finds you all better and ready to battle with the guys... Hope to see you back (Braithwaite et al., 1999).

Sally increased excitation of the bond with Rita by facetiously sketching a context in which the females were to defend themselves against the males. She invoked an animal image, "those ole turkeys" to gloss the men, humorously suggestive of the animal level at which bodies summon response. She was not, of course, implying anything even remotely threatening about the men, so she chose a species considered comical and harmless. Sally kept an edge in her image, however, using a bird with marked sexual differentiation and the hint of antics in the barnyard. In a few lively words, she crafted a warm, funny welcome back for Rita, making clear the intent to refresh the social bond for the express purpose of future communication. 
The welcome for Rita is an example of the need to renew bonds which may have declined over time. Other group members also sent messages such as:

Oh Rita. I'm sorry [about the hospitalization]. All better now? Hugs. (Braithwaite et al., 1999)

The simple but eloquent "Hugs" at the end of the message simulated physical affection, refreshing social bonds for future communication.

\subsubsection{Eating and Drinking Together}

We have explored a non-verbal means of establishing affinity, examining the social bonding that occurs through touch, noting that the impact of touch on communication is not easily captured in notions of messages carried in channels. Eating and drinking together is another arena of communication in which the body is paramount and for which bonding is not fruitfully described as the transfer of information in channels.

The ubiquitous activity of eating and drinking together probably comprises the most fundamental way in which people come to feel connected and reconnected to one another. On one level this is obvious and we all know it from personal experience. We "do lunch," we break bread together, we drink into the wee hours. But in our theories, we have ignored eating and drinking as central to establishing bonds that promote affinity.

Greg managed a small media firm in San Francisco. He explained how bonding occurred between him and his clients through shared meals:

Greg: [Resuming a prior thread in the interview]. We were talking about the lunch/dinner thing. That's, that's kinda where the bonding happens. Especially if we've had a successful pre-pro [pre-production meeting], everybody feels it's gonna be a good job, the agency feels that they've brought their client into a professional house, we've all had our acts together... So then we go out to some fancy restaurant here in San Francisco, which they love, you know, we always try and keep the most trendy, up-to-date kind of thing, and everyone gets a little drunk, and the client generally holds court talking about how hard it is to work for Procter and Gamble, or whatever, you know. It's kind of... they're usually pretty high energy fun.

Why did this dinner occur? The participants had had ample opportunity to collect information on the social presence of others during the pre-production meeting. They had exchanged substantive business information: "...it's gonna be a good job." They had achieved trust: "the agency feels they've brought their client into a professional house." They had done everything the CMC theories predict, in the richest possible medium of face 
to face communication, in the pre-pro meeting that very day. Yet still they sat down to eat a meal together.

The dinner took place, it is argued, to deepen the social bonds among consultant and clients, to increase the level of excitation in the fields of connection in relationships in an active stage of an ongoing project. Social bonding does not happen merely because of face to face communication, but because of specific activities, including eating and drinking, facilitated by face to face experience. Sharing food and drinking are intense bodily activities that stimulate intense social responses, summoning feelings of connection at a deeper, pre-conscious level.

In this interview segment, as in Carl's, we see the juxtaposition of discourse connoting deliberate, detached calculation describing the planning of bonding activity, with less careful, more emotional words suggesting warm human connection. Greg revealed the premeditation with which he had scoped out the special restaurant as the perfect stage for the bonding. But he shifted to chummy phrases about everyone getting a little drunk and having "high energy fun." Greg's planning of the dinner was not the kind of unconscious operational behavior we saw with Alan's quick greeting in IM. However, it set the stage for many such interactions including the convivial loosening of tongues that led to a good time for all.

In an ethnographic investigation of network engineers (those who design and maintain telephony and Internet connectivity), I observed the following on a t-shirt worn by an engineer at a meeting in 2002 of the North American Network Operators Group Conference:

\section{The Internet Works Because We Drink Beer}

This t-shirt wisdom nicely encapsulates the idea of the connections forged between engineers through drinking together, and the necessity of such socializing to the work the engineers do. The favorite event at this conference is a lengthy evening session called "Beer and Gear" in which the engineers socialize (the "beer") and wander around viewing demos of new systems and equipment (the "gear"). It is noteworthy that this face to face conference, whose participants are as intensively involved in the virtual world as anyone possibly could be, takes place three times a year. The engineers value getting to know one another, and staying in touch, as crucial for the work of keeping the Internet going (Nardi, n.d.).

In turning to mediated communication, we find analogs to eating and drinking, just as we did with touch. Fussell conducted a five year study of an online community of people dealing with a serious disease. She documented the practice of simulated eating and drinking (Fussell, 2002). She analyzed the discourse in the community, reporting that $20 \%$ of all communication could be categorized as "small talk." Of that, just over $10 \%$ was about eating. Sometimes people "brought food" to the chat, for example, cookies 
for everyone. Other times they talked about what they were actually eating at the keyboard. There was little talk about food in general, or what participants had eaten in the past. The talk centered around current food activity, consistent with the idea of bonding through eating, rather than a generic interest in food in which the discussion might have ranged further. While the percentage of time devoted to "eating" in the community was small, nonetheless it is remarkable that people would simulate eating in an online forum! Or that they would tell each other what they were consuming as they typed. Provisioning one's remote interlocutors with virtual cookies implies a deeply felt urge to recreate the real experience.

Braithwaite et al. (1999) also reported such actions in the community they studied. One participant, for example, initiated a bond with a new member by inviting,

Come on in, grab your favorite beverage, and sit and talk. Glad to have you here.

Eating and drinking then, take place in both physical and virtual space. While the quality of the experience varies in the two situations, and likely has considerably more impact on stimulating affinity in the real world, it is still striking that people simulate eating and drinking online, in order to capture at least some of the effect of actually sitting down and eating and drinking with others. It seems likely that the more senses one engages in an experience, the more intense it becomes. Further research is needed to investigate more precisely the relationship between sensual activities such as eating and drinking and human communication.

\subsubsection{Sharing Experience in a Common Space}

Another bodily means of social bonding is sharing mutually meaningful experience in a common physical space. In the previous interview segment in which Carl introduced the CEO and the journalist, we saw how the larger media event provided a backdrop for Carl's impromptu staging of the introduction. Carl discussed how he established relationships with the press in part through the shared experience of attending trade shows and other industry events:

Carl: I think you need to come to know them [new press contacts] as a person at some point and have some physical engagement with them, be at the same place for some reason. You know - whether that's a trade show or some industry event or something like that - it's a chance to meet them in that context - what's going on in the industry. But then, it's nice because there's the physical connection which has been fun for me. 
Carl observed that he wanted to "be at the same place for some reason." The creation of the bond was fostered through an experience that involved shared interest in and concerns about "what's going on in the industry." Carl emphasized his sense of physical connection in context, using the word "physical" twice in this short segment, first speaking of "physical engagement" and then "physical connection." These phrases clearly denote the sense of connection that arose through the shared experience in context.

Carl's manager and most of his coworkers were located a continent away, on the opposite coast of the U.S. Describing informal meetings with coworkers when he traveled to their site, Carl noted the "physical engagement" needed to renew bonds in fields of connection he had established with these coworkers:

Carl: You know, in [one] three-day swoop you can hear an awful lot of what's going on in [the remote office] and physically see a lot of these people which you need to do. Same as with the press. You can never cultivate these relationships without physically engaging people as part of it.

Carl observed that "you need to... physically see" and "physically engage" people in order to renew relationships. In theory, Carl should have been able to "hear" what was going on in the remote office on the phone, but in reality, he got the latest gossip and updates face to face in the context of the office. While such engagement is possible with computer-mediated communication, it is often less efficient. Walther and Parks (2002) pointed out that in some cases, the same relational work can be done with CMC, but it may take considerably longer. Note that Carl began his discussion with the phrase "in [one] three-day swoop," emphasizing that he needed to actuate connections quickly and efficiently.

Barry, Carl's manager, and a public relations executive at the telecommunications company, pointed to the shared spatial and experiential nature of communication in his network:

Barry: Well, I think a tremendous amount of the networking that's done on a business level is personal, spatial, geographical. It's being in and of the same space and having the same experience of the surroundings. So I've never experienced a situation in which we've been able to use technology as an effective substitute to travel. Even though we've tried many times - we've done interviews by videoconference with reporters in one city, with [our people] in another city.

Barry emphasized shared physical space as critical to "networking" in his use of the words "spatial" and "geographical," and his mention of having "the same experience of the surroundings." 
Carl recounted how funerals were often a good opportunity for "networking."

Carl: The horrible thing was that we actually went to a wake for somebody .... very beloved speech writer who was a wonderful person...and, you know, we went and paid our respects, and... inevitably of course there's a little bit of networking that goes on there... I hate to say it, but I think that's part of life... And there were PR people [from a former company]...you know, because we came from that common heritage and there still is some connection there.

Again we have a dramatic staging for the renewal of social bonds, intensified by the feelings for the beloved colleague. Reconnections are made with people from the former company. The display of the corpse at wakes may well produce a charged atmosphere in which bonding is especially effective because of the visceral impact of the dead body. The funeral is a variation on the media event; in both settings, the raw presence of bodies in the shared space seemed to heighten intensity, encouraging bonding.

Mediated communication can be crafted to suggest a sense of shared experience in a common space to facilitate bonding. Rachel, a producer at a company that designed Web pages, CD-ROMs, and other media, described how she managed phone communication with contractors working out of their homes:

Rachel: [And] what I try to foster in all of our independent contractors is an allegiance to the company - to this company.

Interviewer: How do you do that?

Rachel: I talk to them... I realize that they are at home in their home setting. I don't call them up and talk business right away. I'll call them up, for example one of my programmers off site is working on fixing up his house. I'll call him up and say, "Hey! How's your floor going?" or "Your windows!" and kind of get into his world. And he'll talk to me and we'll chat about this and that and then I'll get to work stuff. 'Cause I know, I've worked at home before. I know what it's like when you get this business call and you're in your home setting. It's just kind of sometimes invasive or intrusive, and you need to walk a fine line whereby you have that kind of intermediary language. And I don't think it's a ruse. I think it's just a part of conversation that you're meeting each other somewhere.

Rachel was getting into the contractor's space, attempting to insert herself virtually for her own ends which were, quite self-interestedly, to "foster...allegiance ... to this company." She defended her tactical use of 
virtually entering the contractor's space, claiming it was "not a ruse." Rachel was actuating a field of connection via a simulated shared physical space, saying that she and the contractor were "meeting each other somewhere." To Rachel this meeting "somewhere" was intrinsically part of communication; as she said, "...it's just part of conversation that you're meeting each other somewhere."

Instant messaging is used to suggest shared space and the feeling of affinity that creates. Alan discussed monitoring his buddy list for this reason:

Alan: You feel like you know where other people are, so you feel like you're not the only one working on a weekend. To me it's just fascinating to know that someone else is somewhere else doing something while you're doing something. You feel like you're in this world together so this creates a little universe.

Alan's language clearly invokes space; he spoke of occupying a "world," "a little universe," and "knowing where people are." Within that "space" he could experience connection to others: "you're in this world together."

Kathy, an independent marketing consultant, spoke of face to face interaction in similar terms:

Kathy: Well, when you're interacting [face to face], you're much more involved, much more-how am I going to say this? I don't know, it's just more touchy-feely, we're in this together kind of thing.

Alan's phrase "...you're in this world together" is remarkably similar to Kathy's "we're in this together kind of thing." Mediated and face to face communication may evoke similar responses of connection in people as they experience a shared space, be it physical or virtual. While the language of "space" in virtual terms is possibly purely metaphorical, and may thus indicate a qualitatively different experience, nonetheless it is noteworthy that simple text messages (and sometimes sounds in IM) are described as evoking a sense of space, for the purpose of establishing connection, just as in face to face communication.

\subsubsection{Informal Conversation}

Arenas of social bonding involving the body have been examined. Touch, eating and drinking, and experience in shared space all turn on the presence - real or virtual - of the human body. The use of informal conversation for social bonding is now discussed. Informal conversation creates affinity through greetings, jokes, gossip, polite inquiries, and "chatter" of low substantive content. Argyle observed that for "conversation about the weather, or similar vacuous topics... no information is exchanged," but a dyad can begin to form a relationship (Argyle, 1969). 
We have seen how Carl efficiently made his "three-day swoop" through the remote office, relying on the ease of face to face contact to collect office gossip and to make good use of his considerable charm and humor (which I observed in his daily interactions at the office where I conducted the research). Carl often regaled people with anecdotes of his amateur rock band and the famous journalists he knew. He could tell touching stories of his aged mother. Probably few readers need to be convinced of the prevalence of jokes, gossip and informal chat in daily face to face life, so we turn to such interactions in mediated communication, to establish their presence in instant messaging and online communities.

Instant messaging is justly famous for encouraging quick informal greetings that seem to please people out of proportion to the effort it takes to send the messages (Grinter and Palen, 2002; Handel and Herbsleb, 2002; Schiano et al., 2002). In the IM study, Mike, a graphic artist at an Internet portal company, observed:

Mike: My roommate just came online and she can say "Hi." ...[IM] is a nice break from the work that can be mundane. Lana is two cubes away but she messages me all the time. It's a nice way of saying "Hi" without being too intrusive.

At the same company, people often sent "Good morning" messages in IM. They noted that it would have been considered lunacy to deliver a "Good morning" message in email, but that people appreciated a quick IM greeting.

People joke in IM, weaving bits of humor into task-related exchanges. Melissa, Alan's administrative assistant, communicated frequently with him through instant messaging. In the following IM log, Melissa joked about the waywardness of Stan, one of their colleagues:

melissa (8:40:39 AM): Sam will be coming in on June 1 as of this moment alan (8:40:56 AM): oh... not here this fri, eh?

melissa (8:41:11 AM): NO... He is in Hawaii at the moment.

alan (8:41:24 AM): right. . for the shareholders meeting.

melissa (8:42:09 AM): You got it. . .Making Gail crazy needing paperwork from Stan's group yesterday at $4 \mathrm{pm}$ and they are out on an Offsite...

alan (8:42:34 AM): :-)

Melissa was telling Alan that Stan was infuriating Gail regarding the late paperwork that Sam was demanding. Alan returned a smiley face to acknowledge the gossipy joke - he could well imagine Stan disappearing when he had not completed necessary tasks in the office. 
Humor is often used to release tension (Berk et al., 1989). In hierarchical organizations where status differences may add to the tension, jokes such as Melissa's lighten the atmosphere. In a study of technology use in an operating theater during neurosurgery, the authors were surprised to hear rather craven jokes told during routine parts of brain surgeries (Nardi et al., 1996). Interview participants explained that such jokes defused the tensions created by a status hierarchy in which a godlike surgeon occupied an Olympian pinnacle, and other roles descended, in a strict ranking, from there. (It is difficult not to be reminded of the status-conscious capuchin monkeys and their efforts to soothe one another.) The bodily release of tension accompanied by laughing seems to allow people to relax and connect with each another more easily.

Other forms of informal communication include flirting, joking to please friends, and everyday chit-chat. Folk expressions such as "passing the time of day," or "shooting the breeze" mark the existence of low content social communication. Schiano et al. (2002) reported that teens frequently flirted in IM, often with humor. The teens said they talked about "anything and nothing" in instant messaging, chatting about very little when they wanted to "hang out." Informants in the IM study remarked that IM was like "passing notes in school" - more productive of mischievous bonhomie than the transfer of substantive information.

The social bonding through informal conversation in instant messaging and on cell phones is often oriented more toward renewal than creation of bonds. Participants are usually conversing with those they know well, i.e., those on the buddy list or phonelist. Nardi et al. (2002) found that IM buddy lists in the workplace averaged 22 people, with six friends/family and sixteen coworkers. In practice, participants usually interacted with only four or five of the buddies on a frequent basis. Even teenagers, though they may have long lists, typically have a small core group of frequently contacted buddies fewer than five according to several studies. Schiano et al. (2002) reported that teens regularly IMed with fewer than five buddies. Grinter and Eldridge (2003) found fewer than three "regular contacts" among teen users of text messaging in the UK. Ito (2001) reported a similar pattern for Japanese teen users of cell phones.

Handel and Herbsleb (2002) created a hybrid IM/chat system used by workers at a telecommunications equipment manufacturer. Users did not have personal buddy lists; aggregated groups were created and people could then join them. The authors found that about $15 \%$ of the chat was devoted to informal conversation including greetings, humor, and "non-work" discourse such as discussion of hobbies. This is consistent with Fussell's finding that $20 \%$ of the conversation in the community she studied was "small talk" (Fussell, 2002). Handel and Herbsleb (2002) were at pains to point out that $69 \%$ of the exchanges in their system were work-related (to quell critics' 
concerns about the distractions of chat in the workplace). That the preponderance of discourse was work-related does not, however, obviate the importance of the informal conversation so useful for social bonding. That $15-20 \%$ of the discourse was not about the substantive matters at hand is perhaps rather amazing! These interesting quantitative results suggest a pattern in which substantive conversation is preceded by and interspersed with informal conversation enhancing social bonding.

Braithwaite et al. (1999) reported that humor was often used to "ease the early stages of relationship development" in the online disabilities community. They found that sometimes new members had to be explicitly instructed in how to initiate informal conversation to meet people. An experienced member explained to a new member:

A good way to start is to say hello. You can always introduce yourself. Ask them how their day is going... Ask about their hobbies (Braithwaite et al., 1999)

Obviously most adults do not need to be told to "say hello" in the face to face situation. In the new online world, such operational behaviors may move up to the conscious goal level, in activity theory terms, as they are now in a new context in which the habitual actions do not readily apply. The experienced member advised the new member to try the same types of informal conversation for creating social bonds that work in face to face conversation. Ploys such as "How is your day going?" often do not result in the exchange of information of much substance, but they can be effective in making a link for further communication about whatever topics of mutual interest evolve in the conversation.

\subsection{EXPRESSION OF COMMITMENT}

A second dimension of connection is the expression of commitment to participants' mutual relations. Commitment is an engagement denoting scope for ongoing communication for projects of mutual interest. Just "showing up" communicates that one is attending to the relations necessary for carrying out such projects. As we will see in the following interview segments, the expression of commitment is not about actually doing the work or engaging in the mutual project; it is simply about being there. It is argued that face to face communication is the most powerful way to express commitment under normal circumstances. However, under some conditions, mediated communication can also communicate commitment effectively.

Barry, the telecommunications public relations executive, described the importance of face to face communication for "demonstrating commitment":

Barry: And you know, relationships are managed and fed over time, much 
as plants are. [You] demonstrate an enormous amount of unconscious commitment when you actually take the time and the trouble to put yourself in the same place as the person you want to build a relationship with. And if you arrive early at a seminar in advance of the time you're to give a presentation, and if you give a presentation and then remain for an hour or two or the rest of the day and participate in other discussion, that's noted and remarked upon, versus the busy executive who comes in, gives the presentation and leaves, or the person who in some fashion is participating as a disembodied voice over television. The information is still received; but the relationship management aspects are not really... are not really handled at all.

Coming from a telecommunications executive, Barry's insistence that face to face communication is essential to relationship management was a strong statement. He remarked that mediated communication - the "disembodied voice over television" - did not work for relationship management, in his experience. Instead, the presentation of the body was required to achieve the highest expression of commitment. The early arrival at the seminar is likely to be a good time for informal conversation of the sort discussed in the previous section. The "hour or two" after the seminar hold opportunities for substantive discussion, and at the same time, present the participant as committed to ongoing mutual relations, as they are taking "the time and trouble" to stay. If substantive discussion were the sole purpose of the meeting, it could have been conducted over the phone or "on television" as Barry observed. Barry clearly distinguished "the information [being] received" from "the relationship management aspects."

In a similar vein, Nora, an independent public relations consultant, explained why she preferred to work with local clients.

Nora: Well actually I prefer to work with local clients because I think that face to face contact is important. It certainly helps me to see them even every week, but a couple of times a month is good. I think what we call "face time" is very important.

Interviewer: Why is that?

Nora: Because they tell you stuff they don't tell you over the telephone. You see other people in the office. They know that, "Oh, we really do have a PR person, it's not just some disembodied voice out somewhere in Palo Alto."

The disembodied voice again. Both Barry and Nora invoked the body, or rather a missing body, in stating that mediated communication in which a voice has no body did not serve the same ends as face to face communication. Habeas corpus. Nora noted that her clients needed to know that "we really do 
have a PR person." This knowledge could not be established with voice only, but required a body.

Nora also talked about "seeing," as Carl and many other informants did. Bonding and the expression of commitment seem to happen most easily when people see each other in person, with the body in full view. In social presence theory the body is also important, though it is a sense of the specificity of a particular body that is at stake. With showing up, any body (not anybody) will do; it is simply the living flesh that is called for.

Nora explained that for her a regular program of "seeing" was crucial; every week was best, but she could get by with a couple times a month. Barry too had a regularly scheduled program in mind, likened to caring for plants. These remarks return us to the lability of the dimensions of connection, to the ever-present need to refresh and renew connections. Again we see a pattern of constant fluctuation when focusing on the dimensions of connection, rather than the linear progression of a deepening relationship we would observe if looking more globally at a dyadic pair over time.

Kathy, the marketing consultant, worked out of her home. She spoke of the need to leave her home to go see her clients as a way of "replenishing her spirit" with them.

Interviewer: So why do you actually go down to [the customer] site?

Kathy: Well, you have to have face time with people.

Interviewer: Why?

Kathy: They need to see that you're alive (laughs). They do! They need to get reconnected with you. What I've found is that if you don't go and have face time with people periodically, they'll start to make assumptions about you, like very funny, like, "Oh, I couldn't have gotten a hold of Kathy, so she must not be working on my stuff." ...So you need to go kind of be there and say, "Hi, I'm here," you know? You need to share, talk a little bit, and you go on. And it's kind of like replenishing your spirit with them in a way. ... It's their needs. I mean, I can stay here [at home] all day, all alone. I don't have to go see them ... to do my job.

Yet again we see the detached language of calculation as Kathy monitored fields of connection with her clients, coupled with emotional warmth in the vivid statement that she "replenished her spirit" with them. Like Barry, Kathy distinguished "the work" which she could do at home, from relationship management which required that she "go see them." The clients demanded her live body ("see that you're alive") as an assurance that she was really working for them. As a business strategy, Kathy made sure she had 
sufficient face time with clients and that the time was crafted to "share" and "talk," to create opportunities for informal conversation.

Jill worked as a manager at a media company producing animations and web sites. She described how important it was for her and her colleague David to fly from California to Detroit to make a presentation in person:

Jill: You know, I went to Detroit last week. David and I went to L.A. for the day for meetings, then flew on the red-eye to Detroit, came back the next afternoon. And it was all to try to land a job that I knew we had very little chance of getting. But, I felt we had to make the trip to make the presentation, and David did a brilliant presentation. Probably - like maybe we can pull a rabbit out of the hat and get this job - but, I knew that that was a long shot so it was also just a creative connection with them for the future.

Despite knowing they had little chance of getting the job, Jill and David flew from San Francisco to Los Angeles to Detroit in one day. There was no other way to communicate their commitment to a relationship with the prospective client. Though they did not get the job, they achieved a "creative connection" for the future.

There are undoubtedly many interesting power relations involved in summoning the body of another as a condition of free communication in mutually constituted fields of connection. We see from our examples that while those in power may summon the body of others as a necessary grounding for communication, we can also marshal the resources of our own bodies to show up, proactively engaging high levels of commitment, as Barry did, and as Jill and David were trying to do. The use of the body as a kind of trading currency in face to face communication indicates the social relational nature of what is often problematic in communication. As Barry and Kathy pointed out, the "information" they had to offer could be transmitted through mediated means. But the social desires of clients to "see" who they were working with, to find opportunities for small talk, to "get reconnected," often trumped the purely task-related aspects of the work.

Face to face communication is in part an effective way to express commitment because it usually takes more time and effort to appear in person. People are cognizant of the calculus of personal resource allocation, responding positively when people spend scarce resources of time, and sometimes money, to "show up." The other aspects of face to face communication of course also come powerfully into play, including information bandwidth, and the ease of establishing relations of affinity.

Can commitment be expressed with mediated communication? Certainly the answer is yes, though more research is needed to understand the relative power of face to face communication which seems to be overwhelmingly 
effective in showing commitment. However, under some circumstances, people can express commitment in mediated communication.

Lynn, a contract attorney who appealed life sentence cases for the state of California, described how she used U.S. mail and the phone to deal with her clients on death row. When she was starting a case she wrote to the client and offered her phone number:

Lynn: I get a little bit of information about the case and the client's address.

Interviewer: Yeah.

Lynn: I then write to the client. That often starts a letter writing campaign back and forth depending on, you know, how interested in the process the person is. I also accept collect phone calls from them. You can't call somebody who's in prison, but they can call you.

In twenty years of practice, Lynn had met only a handful of her clients face to face. California state government does not fund trips to prisons for contract attorneys, so she used the phone. She felt that she could establish deep rapport with many of her clients through phone conversation:

Interviewer: What about the contact with your clients? Do you ever miss that? That's the first thing I would think of because you work for a client, you want to get an impression who the person is, you want to understand the case from their perspective and all that...

Lynn: No. You know, I think that I do have relationships with certain of them that are very intense. There are others-it really sort of comes from the client. I'm available to them if they want to contact me. I never refuse a phone call, ever, and so I have some people who get to the phone all the time. The woman that I have in Federal Court right now I've been representing since 1994 maybe. She calls me all the time. We've become not exactly friends, but our conversations go far beyond what's going on with her case.

In her policy of never refusing a phone call, "ever," Lynn showed commitment to clients, much as people do with face to face communication. In the case of Lynn and the prisoners, with the peculiar constraints of their situation, the open phone was an effective substitute for commitment usually communicated through face to face communication. The expression of commitment is not a simple outcome of bandwidth in all circumstances, as we saw with Lynn. Theories which straightforwardly assess media in terms of channel "richness" miss the nuances of the relational aspects of communication which vary in complex ways as contexts change. 


\subsection{CAPTURING AND MONITORING ATTENTION}

We now turn to a third dimension of connection, capturing attention. Before communication of any sort, including social bonding and showing commitment, can occur, people must gain the attention of the participant with whom they wish to communicate. Attention capture involves locating the intended recipient (hence the need for awareness information), and either attaining attention through eye contact in a face to face setting and/or sometimes negotiating availability through a verbal exchange for further conversation.

The need for awareness information is amply documented (Heath and Luff, 1991; Mantei et al., 1991; Fish et al., 1992; Bly et al., 1993; Dourish and Bly, 1993; Tang et al., 1994; Tang and Rua, 1994; Gutwin and Greenberg, 1998; Milewski and Smith, 2000; Nardi et al., 2000; Begole et al., 2002; see also the reviews of Walther and Parks, 2002 and Whittaker, 2002). This paper focuses on eye contact (gaze) and negotiating availability in attention capture. As with affinity and commitment, the impact of gaze is not easily expressed in models of information transfer; a more direct linkage via the body appears to be at work.

\subsubsection{Eye Gaze}

There is an extensive literature on eye gaze in psychology, including a seminal paper by Argyle and Dean (1965) demonstrating the "joint arousal" engendered by gaze. Short et al. (1976) summarized experimental research showing that frequent eye contact led to more positive evaluations of conversational partners. Recent work on gaze and CMC continues to support this notion. Vertegaal and Ding (2002), for example, reported that their research "strongly underscores the importance of proper conveyance of eye gaze in [CMC] systems."

In this paper, the focus is on the relationship of gaze to fields of connection. People are often aware of the importance of gaze, and may consciously monitor and control it, as with the other dimensions of connection. Many informants mentioned the importance of eye contact (the term they used). In the netWORK study, Wanda, a technology transfer specialist at TelCo, discussed eye contact in terms that suggest a field of connection:

Wanda: When you're in a conference room and you're at a conference table and all these conversations are going on and people are going back and forth and they look at each other, and they look at the other people in the room, and they're trying to convey a point or trying to persuade someone, uhm, eye contact and body language mean a lot. If your eyes are on a computer, you may as well not even be there. You may as well be a secretary taking notes. 
Wanda explained that simply being colocated does not guarantee the activation of attention in a field of connection. She noted that if your eyes are on your computer, "you may as well not even be there." Wanda invoked a hypothetical secretary who could be physically present, but not really "there," within a field of connection.

Ashley, a producer-manager at a media company, remarked on the specialness of face to face communication for engaging attention by looking people in the eye:

Ashley: And there's also you know, face to face, which - we're all human beings. That's the best way to interact with people is to look them in the eye and talk to them, and, you can't do that over the telephone as easily. Certainly not email. Email!

Ashley suggested that attention is engaged at a deeper level by making eye contact while talking to people. She emphasized that for her, this kind of attention was not achieved on the phone and especially not in e-mail.

Gaze underscores the crucial presence of the body in the work of connection. Physiological measures show the effects of mutual eye contact. Eye contact increases heart rate (Kleinke and Pohlen, 1971) and galvanic skin response (Nichols and Champness, 1971). It has been argued in this paper that making connection for communication occurs in part at a pre-conscious level. These measures show that the body responds to gaze through increased heart rate and galvanic skin response, suggesting physiological bases of the state of heightened arousal underlying the use of the body in the work of connection.

\subsubsection{Negotiating Availability}

Unless scheduled in formal meetings, negotiating conversational availability is an ongoing problem in the work of connection (Kraut et al., 1990; Fish et al., 1992; Tang and Rua, 1994; Whittaker et al., 1994; Whittaker 1995; Nardi et al., 2000; Hudson et al., 2002). A first step is to gather information on a participant's availability (as documented in the literature on awareness discussed above). Actually making the connection for conversation is a second step.

Keith, a marketing manager at TelCo, described how he used instant messaging to get in touch with Stan, an elusive coworker on the opposite coast:

Keith: Last Friday I was on [IM] and left two messages for Stan saying I wanted to come out and talk with his people and got no response. Stan is one of my people on here [on his buddy list] and I saw his "Stannies" come up and said: "Hey Stan. Got time to talk?" And he said, "Darn. When you turn these things on, people actually find you." He had turned it on to get a message from his daughter who 
was having a track meet and he was hoping she would reach him. When he did, I caught him and I asked if we could talk and he said he was busy for five minutes and he'd call me back. He called me and we accomplished what I needed to do for my visit here today.

Stan's responsiveness to Keith was low. Even when he was "found" in instant messaging, Stan was reluctant to communicate, complaining that "people actually find you." Keith persisted, however, negotiating a conversation with the message: "Hey Stan. Got time to talk?" It took three messages, but Keith finally made a connection so that the informational conversation he needed to have with Keith could take place. Part of the work of communicative connectivity is to make sure a conversation happens at all. Keith worked hard to connect with Stan.

Sometimes people in the IM study sent very brief messages such as, "Suzi?" to initiate a conversation. That these were easily ignored by recipients was appreciated if the recipient was busy with other tasks (see also Voida et al., 2002). Ryan, a software developer at the Internet portal company, commented,

Ryan: One thing I like about [IM] is that I'll see a message but I won't have to acknowledge my presence. So I'll respond to them later when I have time.

Instant messages were sometimes used to negotiate availability for conversations in media other than IM, in particular the phone and face to face. While in informants' offices, we observed negotiations such as, "Is this a good time to call?" Rick of TelCo remarked,

Rick: ... a typical[IM] conversation would be talking about "Is X a good time [for a phone conversation]"? [If yes,] we'll upgrade to a phone conversation.

Another TelCo informant said that instant messaging was often "a preamble to a more formal conversation" on the phone. At the Internet portal company, these transitions from IM to phone were incorporated into the proprietary instant messaging system so that people could edit their buddy lists to include phone extensions.

Conversational availability may be monitored and negotiated during the conversation as well as initially. An initiator may test the waters to see if the recipient is ready for more, as in this example from my own log of IM use (recorded during the IM study in the spirit of participant-observation):

BonniNardi (3:43:37 PM): John,

JohnatSun (3:50:19 PM): Hi, I'm back [a seven minute gap before he replies to Bonnie's message] 
BonniNardi (3:50:34 PM): Hey, I'm getting my system reconfigured and lost Sally's AIM name.

JohnatSun (3:50:57 PM): Her name (surprisingly) is Sally Smith (with a space between).

BonniNardi (3:51:07 PM): Duh. Well, thanks. How are things going?

JohnatSun (3:51:27 PM): Umm, a little hectic, not for work stuff, but hey, I have a question, can I call you?

BonniNardi (3:51:31 PM): sure.

JohnatSun (3:51:35 PM): at work?

BonniNardi (3:51:39 PM): yes.

JohnatSun (3:51:51 PM): can you save the trouble of looking up the \#

BonniNardi (3:52:00 PM): 463-7064

Bonnie first negotiated availability with a simple, "John." John was not readily available, but responded when he returned. After Bonnie's task was completed, John suggested a longer conversation on another topic for which a phone call would be required: “...but hey, I have a question, can I call you?"

Handel and Herbsleb (2002) counted messages devoted to negotiating availability in their IM/chat system. Thirteen per cent of the total messages concerned availability. This is a pretty hefty number for actions that do not directly concern the work itself. The authors observed a pattern in which the bulk of the greetings and availability messages occurred in the morning, when people were arriving and work was getting underway. They concluded that use of their system was "primarily focused on work tasks and negotiating availability..." (Handel and Herbsleb, 2002).

\section{Discussion and conclusion}

The work reported here documents the operation of three relational aspects of communication - affinity, commitment, and attention. These dimensions of connection ready people for further communication. The values of the dimensions fluctuate in a field of connection between dyads according to their history of communicative activity.

Non-verbal activity involving the body (touch, eating and drinking, sharing common space, making eye contact, showing up) and low-content informal conversation (greetings, jokes, formulaic comments on the weather, and so forth) create and maintain social bonds of affinity. Commitment is most powerfully established with the presence of the body in shared space in face to face communication. Attention management involves locating the 
intended recipient of the communication, gaining attention through eye contact in the face to face setting, and/or negotiating availability for conversation. Activity to increase the excitation level of the dimensions in a field of connection may be habitual and operational, such as saying "hi." People also consciously monitor fields of connection, aware of the need to manage them. Activation of connections may occur through the deliberate planning of elaborately staged encounters, or by crafting playful or humorous conversation such as Sally's faux battle of the sexes featuring the "ole turkeys." Affinity, commitment, and attention undoubtedly vary culturally in the specific ways in which they are expressed. Further empirical work is needed to understand varying cultural expressions.

The dimensions of connection are ever-changing, requiring ongoing attention. Quantitative studies of conversation in online chat communities demonstrate that significant communicative activity is devoted to relational activities. Handel and Herbsleb (2002) found that 25\% of all messages in their group were of a relational nature including negotiating availability $(13 \%)$, greetings $(7 \%)$, and humor $(5 \%)$. Fussell found that relational messages including greetings (12\%) and small talk (20\%) accounted for $32 \%$ of the conversation in the chat she studied. In these two investigations, about one-quarter to one-third of the messages were relational. It is not surprising that the percentage is higher in Fussell's group since it was an emotional support group for people dealing with a stressful illness (Fussell, 2002).

Of special importance is the lability of the dimensions of connection in contrast to general feelings of closeness and familiarity which are described as increasing linearly over time (Altman and Taylor, 1973). Future research is needed to analyze cycles of decay and renewal in dimensions of connection. It is predicted that quantitative analysis will reveal decay and renewal to be asymmetrical, with relatively smaller efforts needed to renew even long dormant contacts.

The data from the netWORK study (Nardi et al., 2002) showed the importance of the body in managing the dimensions of connection in face to face communication. It has been argued that touch, eating and drinking, sharing experience in a common space, and eye contact are not straightforwardly informational, having impact at a pre-conscious, even physiological level (as in eating and drinking or the arousal caused by eye contact). The presence of other bodies may heighten engagement, intensifying relational communication. CMC theory centered on the bandwidth of media misses the importance of the particular uses of the body identified here as critical to making connection for communication.

These uses of the body do not resolve to "non-verbal codes" as CMC theories specify (see Walther and Burgoon, 1992), but appear to operate at a pre-linguistic level. If there were a code, it could be specified. Informants in the IM and netWORK studies did not discuss any kind of coding; they 
simply talked, often with emotion, but also with vagueness and hesitation, about the use of the body in communication. Such vagueness and hesitation indicate the difficulty of putting into words what is experienced with the body. That the body came up as a topic of discussion repeatedly, and with emotional intensity, suggests its importance, however difficult it may be to articulate exactly what is happening.

While further research is needed to understand the odd combination of intensity and vagueness characteristic of much experience of the body in the work of connection, some interesting clues come from Argyle's work. In his seminal book Social Interaction, Argyle observed, "Language appears to have evolved as a specialized means of communication, but it is used to negotiate the matters being discussed, not the relation between the speakers" (Argyle, 1969). Argyle noted that both human and non-human primates use the body in various ways (grooming, gaze, sexual display, and so forth) to connect socially. He argued that the vagueness of the meaning of such activities is advantageous. Participants are not committed to "an explicit degree of intimacy or inferiority in relation to another" (Argyle, 1969). Nonverbal activity gets the job of connection done, but does not over-commit participants in terms of emotional closeness or status relations.

This vagueness characterized the way touch, gaze, and the presence of bodies were discussed in the IM and netWORK interviews. Informants related stories in which bodies were important, but they did not talk about specific messages that may or may not have been sent. Argyle's point is that there is no one clearly specified "message" emanating from bodily engagement. But neither is there an infinite number of possibilities. The body resolves to a few key human experiences: healing, comfort, sex, and nurturing on the positive side, and aggression under conditions of conflict on the negative side (Argyle, 1969). For touch to wear its semantics on its sleeve and declare a specific intent would hinder the work of connection, as Argyle argued. The vague suggestion of something good, rather than a more specific commitment about what that something might be, seems to allow people to connect for everyday interaction, without getting entangled in potentially difficult issues of intimacy or status.

The work of connection is complementary to the accomplishment of common ground. Both are needed for sustained communication. Common ground concerns shared information, while the work of connection is relational. Each has a distinctive temporal pattern. For common ground, a new piece of information leads to increased common ground, linearly over time. Dimensions of connection, on the other hand, show a decay function, and require replenishment as the degree of engagement of the dimensions diminishes over time.

Establishing common ground and maintaining connection differ in another way. Because the body is brought to bear in fields of connection, each action 
must actually be physically carried out - shaking a hand, having a beer, showing up for a meeting. With common ground, less work may take participants quite a bit further. Propositional knowledge can be inferred (Clark, 1992). So, for example, if I say, "I am from Ohio," someone who knows that part of the country may make inferences about what I probably know (information about Buckeyes, football, the colors of autumn leaves, and so forth). The inferences are likely to be more or less right. (The idea of common ground would not take us far if each statement had to be explicitly expanded, endlessly. The whole idea is that we "get it" with a quick sketch.) The inferences of my interlocutor require no work on my part except revealing my home state. Common ground can grow rapidly with the exchange of relatively small amounts of information. Future research should aim to integrate Clark's theory of common ground and work on the dimensions of connection.

Another question for future research is: Do all conversations have connective and informational aspects? Obviously, it is possible to strike up a conversation with a stranger on an airplane, knowing that sustained interaction is unlikely. Do activities of connection nonetheless come into play? If so, are they different than in other conversations with greater likelihood of longevity? Do people who know each other so well they finish each other's sentences engage in activities of connection? The present investigation can only pose such questions. The author is engaged in experimental research drawing on the work of Tomlinson (2002) to partially address these questions.

When we discover virtual eating and drinking, the invocation of space in mediated communication, and online hugs and pats, we see people using the same strategies in the mediated context that have worked face to face. Although it could change in the future, to date people have learned to communicate through face to face interaction, and then, in the modern world at least, they begin to learn forms of mediated communication. The power and primacy of face to face communication provide the model for at least some of what can be observed in the mediated context. We do not know the nature of the transformation from embodied to virtual bodily experience, but the present work suggests this transformation is a key problem in understanding mediated communication. Rather than undermining the importance of embodied experience for communication, simulated bodily experiences suggest that the impact of embodied experience is so great that people attempt to mimic it in the mediated context.

The quality of experience changes as we move from embodied to virtual, yet the results of the transformation often achieve the intended aims. Future research is needed to uncover the ways virtual experience accomplishes relational work when the actual body is not in play. How are bodily experiences appropriated for virtual use? Is it the power of metaphor? Or the understanding of what the participant intended to simulate? Clearly humans 
have an enormous capacity for virtual experience: dreams, stories, artwork, the self-induced hallucinations of drugs, playing online games. Explaining how and why we move from embodied communicative experience to virtual counterparts is an important line of investigation.

Sometimes communicative strategies of simulation perform extraordinarily well even in the thinnest of media (who could resist Sally's entreaties?). That these transformations can take place effectively in text and voice suggests that an over-emphasis on information richness, informational affordances, and media bandwidth is misplaced. At the same time, the impact of face to face experience remains unique. Popular discourse retains a clear distinction between "RL" (real life) and what is experienced online, even among younger people who have been raised on a steady diet of technology. The efficiency of face to face communication in supplying high impact bodily experiences that promote affinity, commitment, and attention is undeniable. While face to face communication is most certainly information rich in valuable ways, the relational aspects of communication are also efficiently served with face to face communication.

Ashley distinguished the relational impact of gaze in face to face communication from the informational impact of mutually viewable objects and the ability to read facial expressions (classic foci of bandwidth theories) in the following discussion:

Ashley: Well, there's nothing like everybody being in the same place and working on the same problem. It's just - there's an immediacy that you're never far away from what's going on, whereas when people are off site, it takes a lot more management time because you've got to [keep track of things]. On the phone, or setting up those meetings, it's harder to check in on the minute process of a project ... Every time you walk to the back of the office, you are passing someone's computer and you see what they are working on, you see what the mood is on their face. You know, if a question comes up you can ask that person as opposed to writing yourself a note to e mail them or call them later on. It definitely facilitates interaction, there's no question about it. And there's also you know, face to face, which - we're all human beings. That's the best way to interact with people is to look them in the eye and talk to them, and, you can't do that over the telephone as easily. Certainly not email. Email!

And, as Barry said in comparing mediated to face to face communication:

The information is still received; but the relationship management aspects ... are not really handled at all. 
Face to face communication appears to uniquely afford touch, gaze, and shared bodily activity in heightened form. When relational efficiency is paramount, face to face communication has been measured as uniquely productive (Herbsleb et al., 2000; Olson and Olson, 2000; Mark, 2001; Olson et al., 2002). As the Olsons (2000) put it so concisely, "Distance matters."

I am generally in sympathy with arguments confirming the uniqueness of face to face communication. However, the issues are subtle and far from resolved. Walther and Parks (2002) suggested, "When interaction time is not restricted, people in online settings should ultimately reach, although more slowly, levels of impression and relational development similar to what they would reach in [face to face] settings." Walther and Parks' view thus opposes that of the "distance matters" camp, indicating that time is of the essence, not mode of communication. Still, even Walther and Parks acknowledged the relative inefficiency of online communication compared to face to face, while arguing for the relational possibilities of mediated communication.

These findings should send a cautionary message about realities for workers in today's world. The need for speed and cost saving encourages distributed work, necessitating mediated communication, and yet the clocks tick faster, the deadlines grow shorter. The use of short term "virtual teams" and matrixed organizational schemes means workers have less time to get to know one another. We do not yet know the long term effects that attenuated social relations in the workplace may have, but there are certainly hidden costs involved (Sarbaugh-Thompson and Feldman, 1998; Schwarz et al., 1999; see also Walther, 2002 on the importance of temporal effects in communication).

In settings with more time and less intense pressure, mediated communication can be extraordinarily successful, at least under some circumstances. In the online communities devoted to disabilities and serious illness, the goal was to find people with like experiences, and communicate with them, rather than to promote the deepest levels of affinity, commitment, and attention as quickly as possible. While Carl, Barry, Kathy, Nora, and others in a business context needed to connect as fast as they could, the chat communities were well served simply by finding others sharing the same life problem and talking to them, something that would have been difficult face to face for many practical reasons.

Sustained human communication is readied by the creation and renewal of social bonds of affinity, the establishment of commitment, and the capture of attention. These fragile linkages demand our constant engagement, both conscious and unconscious. They bind us in mutually constituted fields of connection within which we communicate and collaborate in everyday activity. 


\section{Acknowledgements}

I would like to thank three anonymous reviewers for their thoughtful critique and helpful suggestions. Many thanks to the following individuals and groups for useful feedback on earlier drafts: JoAnn Brooks, Benjamin Colby, Susan Fussell, Jeff Hancock, Gitte Jordan, Gary Olson, Diane Schiano, Nikki Shechtman, John Tang, Bill Tomlinson, the Ethnography and Design Breakfast Club of Silicon Valley, and LowellCHI, Lowell, Massachusetts.

\section{References}

Altman, I. and Taylor, D. (1973): Social Penetration: The Development of Interpersonal Relationships. New York: Holt, Rinehart and Winston.

Argyle, M. and J. Dean, (1965): Eye-Contact, Distance and Affiliation. Sociometry, Vol. 28, pp. 289-304.

Argyle, M. (1969): Social Interaction. Chicago: Atherton/Aldine.

Argyle, M. and J. Graham, (1977): The Central Europe Experiment - looking at Persons and Looking at Things. Journal of Environmental Psychology and Nonverbal Behaviour, Vol. 1, pp. 6-16.

Baumeister, R. and M. Leary, (1995): The Need to Belong: Desire for Interpersonal Attachments as a Fundamental Human Motivation. Psychological Bulletin, Vol. 3, pp. 497-529.

Barrett, S., T. Henzi, J. Weingrill, L. Lycett and R. Hill, (2000): Female Baboons Do Not Raise the Stakes But They Give as Good as They Get. Animal Behaviour, Vol. 59, pp. 763-770.

Begole, J., J. Tang, R. Smith and N. Yankelovich, (2002): Work rhythms: Analyzing Visualization of Awareness Histories of Distributed Groups. CSCW 2002, New Orleans, LA.

Berk L., S. Tan and W. Fry, (1989): Neuroendocrine and Stress Hormone Changes during Mirthfull Laughter. American Journal Medical Science, Vol. 298, pp. 390-396.

Bos, N., J. Olson, D. Gergle, G. Olson and Z. Wright, (2002): Effects of Four ComputerMediated Communications Channels on Trust Development. Proceedings CHI2002. New York: ACM Press, pp. 135-139.

Bly, S. (1988): A Use of Drawing Surfaces in Collaborative Settings. In Proceedings of Conference on Computer Supported Cooperative Work, New York: ACM Press, pp. 250-256.

Bly, S., S. Harrison and S. Irwin, (1993): Media Spaces: Bringing People Together in a Video, Audio and Computing Environment. Communications of the ACM, Vol. 36, pp. 28-45.

Bradner, E., W. Kellogg and T. Erickson, (1999): The Adoption and Use of BABBLE. Proceedings ECSCW'99, European Conference on Computer Supported Cooperative Work. Dordrecht, The Netherlands: Kluwer Academic Publishers, pp. 139-158.

Braithwaite, D., V. Waldron and J. Finn, (1999): Communication of Social Support in Computer-mediated Groups for People with Disabilities. Health Communication, Vol. 11 no. (2), pp. 123-151.

Carpenter, C. (1942): Sexual Behaviour of Free-Ranging Rhesus Monkeys, Macaca mulatta. Journal of Comparative Psychology, Vol. 33, pp. 113-162.

Clark, H. (1992): Arenas of Language Use. Chicago: University of Chicago Press.

Churchill, E. and S. Bly, (2000): Culture vultures: Considering Culture and Communication in Virtual Environments. SIGGroup Bulletin, Vol. 21, No. 1. New York: ACM Press, pp. $6-11$. 
Culnan, M. and M. Markus, (1987): Information Technologies. In F. Jablin, L. Putman, K. Roberts, and L. Porter (eds.): Handbook of Organizational Communication: An Interdisciplinary Perspective. Thousand Oaks: Sage.

Daft, R. and R. Lengel, (1984): Information Richness: A New Approach to Managerial Behavior and Organizational Design. In B. Straw and L. Cummings (eds.): Research in Organizational Behaviour. Greenwich, CT: JAI Press.

Dourish, P. and V. Bellotti, (1992): Awareness and Coordination in Shared Workspaces. In Proceedings of the ACM Conference on Computer-Supported Cooperative Work CSCW'92. New York: ACM Press, pp. 107-114.

Dourish, P. and S. Bly, (1993): Portholes: Supporting Awareness in a Distributed Work Group. Proceedings of CHI'93 Human Factors in Computing Systems. New York: ACM Press, pp. 541-547.

Dourish, P. (2001): Where the Action is: The Foundations of Embodied Interaction. Cambridge: MIT Press.

Ekman, P. (1982): Emotion in the Human Face. New York: Cambridge University Press.

Finn, K., A. Sellen and S. Wilbur, (1997): Video-mediated Communication. Mahwah, NJ: Lawrence Erlbaum.

Fish, R., R. Kraut, R. Rootand and R. Rice, (1992): Evaluating Video as a Technology for Informal Communication, In Proceedings of CHI'92 Human Factors in Computing Systems. New York: ACM Press, pp. 37-48.

Fussell, S. (2002): An Alternative Conceptualization of the Benefits of Bandwidth. Paper presented at "Beyond Face to Face" Workshop, Computer-supported Collaborative Work Conference, New Orleans, 2002.

Garfinkel, H. (1967): Studies in Ethnomethodology. New York: Prentice Hall.

Grinter, B. and M. Eldrige, (2003): Wan2tlk?: Everyday Text Messaging. Proceedings CHI2003. Fort Lauderdale, Florida, pp. 441-448.

Grinter, R. and L. Palen, (2002): Instant Messaging in Teen Life. Proceedings CSCW 2002. New Orleans, pp. 21-30.

Gutwin, C. and S. Greenberg, (1998): Effects of Awareness Support on Group Usability. Proceedings CHI'98. Los Angeles, CA. New York: ACM Press, pp. 511-518.

Handel, M. and J. Herbsleb, (2002): What is Chat doing in the Workplace? Proceedings $C S C W$ 2002. New Orleans, pp. 1-10.

Harlow, H. and M. Harlow, (1962): Social Deprivation in Monkeys. Scientific American, Vol. 207, pp. 136-146.

Heath, C. and P. Luff, (1991): Disembodied Conduct: Communication through Video in a Multimedia Environment. In Proceedings of CHI'91 Human Factors in Computing Systems. New York: ACM Press, pp. 99-103.

Heath, C. and P. Luff, (1992): Collaboration and Control: Crisis Management and Multimedia Technology in London Underground Line Control Rooms. Computer Supported Cooperative Work. Vol. 1, no. (1-2), pp. 69-94.

Herbsleb, J., A. Mockus, T. Finholt and R. Grinter, (2000): Distance, Dependencies and Delay in a Global Collaboration. Proceedings Computer-supported Cooperative Work. New York: ACM Press, pp. 319-328.

Hobbs, J. (1980): Interactive Discourse: Influence of the Social Context. Proceedings 18th Annual Meeting of the Association for Computational Linguistics, June 19-22. University of Pennsylvania, Philadelphia, PA.

Hudson, J., J. Christensen, W. Kellogg and T. Erickson, (2002): "I'd be Overwhelmed, but it's Just One More Thing To Do": Availability and Interruption in Research Management. Proceedings CHI2002. New York: ACM Press, pp. 97-104. 
Iacono, S. and S. Weisband, (1997): Developing Trust in Virtual Teams. In Proceedings 30th HICSS Conference. pp. 412-420.

Ito, M. (2001): Mobile Phones, Japanese Youth, and the Re-placement of Social Contact. Proc. Annual Meeting for the Society for the Social Studies of Science. Cambridge, MA.

Kahneman, D. (1973): Attention and Effort. New Jersey: Prentice Hall.

Kaptelinin, V. (1996): Activity Theory: Implications for Human-Computer Interaction. In B. Nardi (ed.): Context and Consciousness: Activity Theory and Human-Computer Interaction. Cambridge: MIT Press, pp. 103-116.

Karttunen, L. and S. Peters, (1975): Conventional Implicature of Montague Grammar. Berkeley Linguistic Society. Vol. 1, pp. 266-278.

Kiesler, S., J. Siegel and T. McGuire, (1984): Social Psychological Effects of Computermediated Communication, American Psychologist. Vol. 39, pp. 1123-1134.

Kleinke, C. and P. Pohlen, (1971): Affective and Emotional Responses as a Function of Other Person's Gaze and Cooperativeness in a Two-Person Game. Journal of Personal Social Psychology, Vol. 7, pp. 308-313.

Kraut, R., R. Fish, R. Root and B. Chalfonte, (1990): Informal Communication in Organizations. In S. Oskamp and S. Spacapan (eds): People's Reactions to Technology in Factories, Offices and Aerospace. New York: Sage.

Kraut, R., D. Gergle and S. Fussell, (2002): The Use of Visual Information in Shared Visual Spaces: Informing the Development of Virtual Co-presence. Proceedings Computersupported collaborative work 2002. New Orleans, LA. New York: ACM Press, pp 31-40.

Kraut, R., M. Miller and J. Siegel, (1996): Communication in Performance of Physical Tasks: Effects on Outcomes and Performance. In Proceedings of the Conference on Computer Supported Cooperative Work. New York: ACM Press, pp. 57-66.

Lenhart, A., L. Rainie and O. Lewis, (2001): Teenage Life Online: The Rise of the Instant Message Generation and the Internet's Impact on Friendships and Family Relationships. Pew Internet and American Life Project. June 20, 2001. http://www.pewinternet.org/.

Mantei, M., R. Baecker, A. Sellen, W. Buxton, T. Milligan and B. Wellman, (1991): Experiences in the Use of a Media Space. In Proceedings of CHI'91 Human Factors in Computing Systems, New York: ACM Press, pp. 203-209.

Mark, G. (2001): Extreme Collaboration. Communications of the ACM, December 2001.

Milewski, A. and T. Smith, (2000): Providing Presence Cues to Telephone Users. Proceedings CSCW 2000, Philadelphia, PA, pp. 89-96.

Moran, T., W. van Melle and P. Chiu (1998): Tailorable Domain Objects as Meeting Tools for an Electronic Whiteboard. Proceedings CSCW'98 Conference. New York: ACM Press, pp. 295-304.

Morley, I. and G. Stephenson (1969): Interpersonal and Interparty Exchange. A Laboratory Simulation of an Industrial Negotiation at the Plant Level. British Journal of Psychology, Vol. 60, pp. 543-545.

Morley, I. and G. Stephenson (1970): Formality in Experimental Negotiations: A Validation Study. British Journal of Psychology, Vol. 61, pp. 383-384.

Mynatt, E., T. Igarashi, W. Edwards and A. LaMarca (1999): Flatland: New Dimensions in Office Whiteboards. Proceedings CHI'99. New York: ACM Press, pp. 346-353.

Nardi, B., A. Kuchinsky, S. Whittaker, R. Leichner and H. Schwarz (1996): Video-as-data: Technical and Social Aspects of a Collaborative Multimedia Application. The Journal of Computer-supported Cooperative Work, Vol. 4, 1, pp. 73-100.

Nardi, B. (1998): Introduction to A Web on the Wind: The Structure of Invisible Work, A Special Issue of Computer-supported Cooperative Work, Vol. 8, 1-2.

Nardi, B., S. Whittaker, and E. Bradner (2000): Interaction and Outeraction: Instant Messaging in Action. Proceedings CSCW 2000, pp. 79-88. 
Nardi, B. and S. Whittaker (2002): The Place of Face to Face Communication in Distributed Work. In P. Hinds and S. Kiesler (eds): Distributed Work. Cambridge: MIT Press.

Nardi, B., S. Whittaker and H. Schwarz (2002): NetWORKers and their Activity in Intentional Networks. The Journal of Computer-supported Cooperative Work, Vol. 11, no. 1-2. pp. 205-242.

Nardi, B. (n.d.): Cultures of connection: Network engineers and the Internet. Unpublished ms.

Nichols, K. and B. Champness (1971): Eye Gaze and GSR. Journal of Experimental Social Psychology, Vol. 7, pp. 623-626

Olson, G. and J. Olson (2000): Distance Matters. Human-computer Interaction, Vol. 15, pp. $139-179$.

Olson, J., S. Teasley, L. Covi and G. Olson (2002): The (currently) Unique Advantages of Collocated Work. In P. Hinds and S. Kiesler, (eds): Distributed Work. Cambridge: MIT Press, pp. 113-135.

Parr, L., M. Matheson, I. Bernstein and F. de Waal (1997): Grooming Down the Hierarchy: Allogrooming in Captive Brown Capuchin Monkeys, Cebus appella. Animal Behavior, Vol 54, pp. 361-367.

Rutter, M. (1987): Communicating by Telephone. Oxford: Pergamon Press.

Sacks, H., E. Schegloff and G. Jefferson (1978): A Simplest Systematics for the Organization of Turn Taking for Conversation. Language, Vol. 50, no. 4, pp. 696-735.

Sacks, H. (1992): In G. Jefferson (ed.): Lectures on Conversation. Vols. I \& II, Oxford: Basil Blackwell.

Sarbaugh-Thompson, M. and M. Feldman (1998): Electronic Mail and Organizational Communication: Does Saying "Hi” Really Matter? Organizational Science, Vol. 9, no. 6, pp. 685-698.

Schwarz, H., B. Nardi and S. Whittaker (1999): The Hidden Work in Virtual Work. Proceedings Critical Management Conference, Manchester, July 1999.

Schiano, D., S. Ehrlich and K. Sheridan (2001): Categorical Perception of Facial Affect: An Illusion. Extended Abstracts of ACM CHI 2001 Conference on Human Factors in Computing Systems. NY: ACM, pp. 299-300.

Schiano, D., C. Chen, J. Ginsberg, U. Gretarsdottir, M. Huddleston and E. Isaacs (2002): Teen Use of Messaging Media. Extended Abstracts of ACM CHI 2002 Conference on Human Factors in Computing Systems. NY: ACM, (pp. 594-595).

Short, J., E. Williams and B. Christie (1976): The Social Psychology of Telecommunications. London: Wiley Press.

Sproul, L. and S. Kiesler (1986): Reducing Social Context Cues: Electronic Mail in Organizational Communication. Management Science, Vol. 32, pp. 1492-1512.

Stalnaker, R. (1978): Assertion. In P. Cole (ed.): Syntax and Semantics, Vol. 9: Pragmatics. New York: Academic Press, pp. 315-332.

Tang, J., E. Isaacs and M. Rua (1994): Supporting Distributed Groups with a Montage of Lightweight Interactions. In Proceedings of Conference on Computer Supported Co-operative Work, New York: ACM Press, pp. 23-34.

Tang, J. and M. Rua (1994): Montage: Providing Teleproximity for Distributed Groups. In Proceedings of CHI'94 Human Factors in Computing Systems. New York: ACM Press, pp. $37-43$.

Tang, J., N. Yankelovich, J. Begole, M. Van Kleek, F. Li and J. Bhalodia (2001): CoNexus to Awarenex. Proceedings of the Conference on Computer-Human Interaction (CHI) 2001, March 31-April 5, 2001, Seattle, WA, ACM Press, NY, pp. 221-228.

Tomlinson, W. (2002): Synthetic Social Relationships for Computational Entities. Ph.D. Dissertation, Cambridge: MIT. 
Trevino, L., R. Lengel and R. Daft (1987): Media Symbolism, Media Richness, and Media Choice in Organizations. Communication Research, Vol. 14, no. 5, pp. 553-574.

Vertegaal, R. and Y. Ding, (2002): Explaining Effects of Eye Gaze on Mediated Group Conversations: Amount or Synchronization? In Proceedings of Conference on Computer Supported Co-operative Work. New York: ACM Press, pp. 41-48.

Voida, A., W. Newstetter, and E. Mynatt (2002): When Conventions Collide: the Tensions of Instant Messaging Attributed. Proceedings CHI2002. New York: ACM Press, pp. 187-192.

Walther, J. (1992): Interpersonal Effects in Computer-mediated Communication: A Relational Perspective. Communication Research, Vol. 19, pp. 52-90.

Walther, J. and J. Burgoon (1992): Relational Communication in Computer-mediated Interaction. Human Communication Research, Vol. 19, no. 1, pp. 59-88.

Walther, J. (2002): Time Effects in Computer-mediated Groups. In P. Hinds and S. Kiesler (eds): Distributed Work. Cambridge: MIT Press, pp. 235-257.

Walther, J. and M. Parks (2002): Cues Filtered Out, Cues Filtered in: Computer-mediated Communication and Relationships. In M. Knapp, J. Daly and G. Miller, (eds.): The Handbook of Interpersonal Communication (3rd ed.): Thousand Oaks, CA: Sage.

Weisband, S. (2002): Maintaining Awareness in Distributed Team Collaboration: Implications for Leadership and Performance. In P. Hinds and S. Kiesler (eds.): Distributed Work. Cambridge: MIT Press, pp. 312-333.

Whittaker, S. (1995): Rethinking Video as a Technology for Interpersonal Communication. International Journal of Human Computer Studies, Vol. 42, pp. 501-529.

Whitttaker, S. (2003): Theories and Methods in Mediated Communication. In A. Graesser (ed.): The Handbook of Discourse Processes. Cambridge: Hillsdale NJ: Lawrence Erlbaum.

Whittaker, S., D. Frohlich and W. Daly-Jones (1994): Informal Workplace Communication: What is it Like and How Might We Support It? Proceedings of CHI'94 Conference on Human Factors in Computing Systems. New York: ACM Press, pp. 131-137.

Whittaker, S., E. Geelhoed and E. Robinson, (1993): Shared Workspaces: How do they Work and When are they Useful? International Journal of Man-Machine Studies. Vol. 39, pp. 813-842.

Williams, E. (1977): Experimental Comparisons of Face-to-Face and Mediated Communication. Psychological Bulletin, Vol. 16, pp. 963-976.

Zheng, J., E. Veinott, N. Bos, J. Olson and G. Olson, (2002): Trust Without Touch: Jumpstarting Long-distance Trust with Initial Social Activities. Proceedings CHI2002. New York: ACM Press, pp. 141-146. 